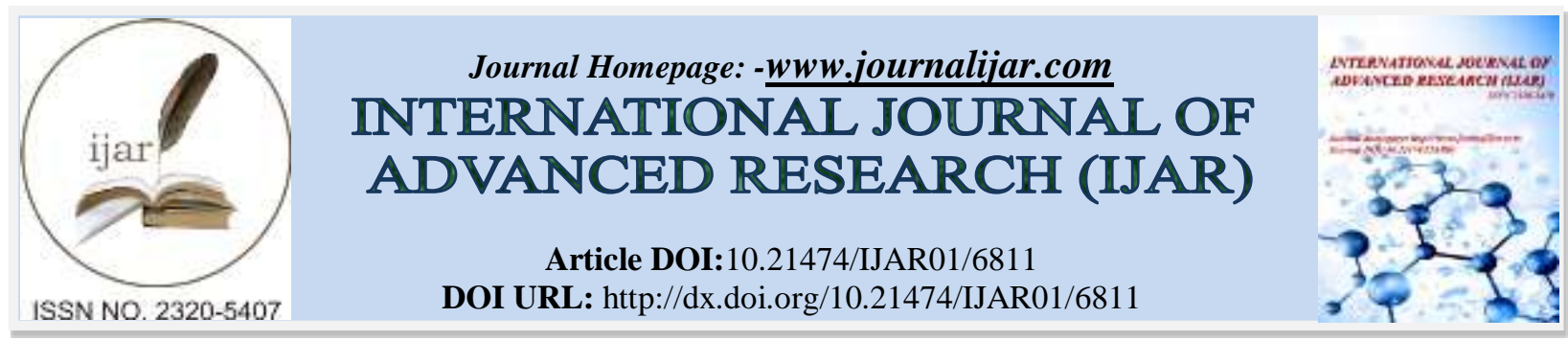

RESEARCH ARTICLE

\title{
AN ONCOPLASTIC APPROACH USING INFRAMAMMARY TRANSPOSITION FLAP TO REPLACE PARTIAL MASTECTOMY DEFECTS.
}

\author{
Ahmed F. Al Karmouty ${ }^{1}$, Ahmed E. Shaaban ${ }^{1}$, Ehab M. Elzawawy ${ }^{2}$ and Melad N. Kelada ${ }^{2}$. \\ 1. Surgery, Medical Research Institute, Alexandria University, Alexandria, Egypt. \\ 2. Anatomy And Embryology, Faculty of Medicine, Alexandria University, Alexandria, Egypt.
}

\section{Manuscript Info}

Manuscript History

Received: 22 January 2018

Final Accepted: 24 February 2018

Published: March 2018

Inframammary - transposition - flaps oncoplastic - breast - surgery.
Keywords:-

\begin{abstract}
Introduction: resection of inferior breast tumors may result in substantial deformity. Inframammary tongue shaped adipofascial flaps (AFPs) were proposed to reconstruct inferior defects but the vascularity of these flaps are not certain. Anatomical studies in our institution favored medial and lateral vascular routes to superiorly based flaps.

Aim of the work: to evaluate the safety and adequacy of inframammary transposition flaps (IMTFs) based on medial and lateral vascular roots to reconstruct defects in the inferior breast following breast conservative surgery.

Patients and methods: Ten patients with small to moderate breast sizes and inferior tumors under went wide resection to negative margins through an inframammary line (IML) incision. The excess tissues below the IML were used as transposition flaps medially or laterally based (according to tumor position). These flaps were moved into breast superiorly to replace defects. The rate of complications and esthetic outcomes were presented.

Results: low rates of fat necrosis and other complications coupled with excellent esthetic results were obtained.

Conclusions: IMTFs are safe and reliable means of oncoplastic breast surgery with accepted complications and satisfaction rates.
\end{abstract}

Copy Right, IJAR, 2018,. All rights reserved.

\section{Introduction:-}

Breast conservative surgery (BCS) is the gold standard therapy for early breast cancer ${ }^{(1)}$. While performing wide excision for breast tumors, it is important to achieve a balance between safety and esthetic outcomes ${ }^{(2)}$. The more the surgeon removes from the breast tissues, the more likely that breast deformity to occur ${ }^{(3)}$.

The inferior breast quadrants are the most liable to deformity and the most difficult to reconstruct. Few options are available to deal with defects in the inferior breast. They include superior pedicle mammoplasty, B mammaplasty and inferior rotation mammoplasty. These techniques involve rearrangement of breast tissues by volume displacement. They are only feasible in large and moderately large breasts. These techniques also involve reallocation of nipple areola complex (NAC). When reduction of breast volume occurs, reduction of the other breast for symmetry may be necessary ${ }^{(4)}$.

Corresponding Author:- Ahmed F. Al Karmouty. 
In small breasts, these techniques are difficult to do because the remaining breast tissues are not enough to constitute a breast mound. Volume replacement of these defects using the tissues nearby the breast is more valuable because it obviates the need for tissue rearrangements, NAC reallocation and contralateral reduction surgery ${ }^{(5)}$.

Inframammary adipofascial flaps (AFP) was proposed as a means to accomplish these goals. Asian populations may be suitable candidates because of small breasts and bulky inframammary tissues. Many authors reported on the use of AFP as an adjuvant to BCS for tumor resections ${ }^{(7)}$. Some used them as ameans of total breast reconstruction ${ }^{(8)}$. Others used them to cover implants ${ }^{(9)}$.

The design of these flaps was somewhat constant. Authors used an inframammary incision to get access for both tumor excision and AFP harvest. After elevation of a skin flap at the level of Scarpe's fascia below the inframammary line (IML), a tongue shaped superiorly based flap was developed to include the fat deep to Scarpe's fascia and the rectus abdonimus fascia. The flap was elevated off the muscle, flipped over to be inserted cranially into the breast above the $\mathrm{IML}^{(7-9)}$.

This design mandated that blood supply of the flap was derived from the subcutaneous vessels at the IML. These vessels were the only potential suppliers because of the medial, lateral and inferior separation of the flap. The blood vessels of the of the skin were not potential suppliers of AFP because of skin undermining.

Although results were encouraging by those authors to use such innovative flaps, the esthetic results deemed to be excellent and durable even after radiotherapy, no study commented on the incidence of fat necrosis after AFPs.

We tried to perform these procedures in our institution using the same design described by those authors, but many of our patients had fat necrosis of these flaps and many more had fat necrosis after receiving radiotherapy. Concerns about the inadequacy of blood supply of these flaps were raised. This initiated our anatomical research for the available vascular roots to flaps in the submammary area.

After dissection of ten female cadavers on either side, it was revealed that superior vascular roots were the smallest in diameter and shorter in length when compared to medial and lateral roots ${ }^{(10)}$. These findings were consistent to our clinical results.

\section{Aim of the work:-}

We wanted to examine the clinical relevance of these anatomical postulations by using inframammary flaps that are medially or laterally based to replace inferior breast defects that result from tumor excision.

\section{Material and methods:-}

Ten patients with tumors in the inferior portion of the breast who had criteria compatible with BCS were chosen to do tumor excision and reconstruction of the defects by infra mammary transposition flaps (IMTFs).

The design of the flap was planned as a transposition flap; the base of it was determined by the position of the tumor i.e. Medial tumors needed medially based flaps while lateral tumors needed laterally based flaps.

The upper limit of the flap was exactly at the IML. The length of the flap was determined by the area of tumor resection superior to the IML and by the extent of excess tissues below the IML. The base to length ratio did not exceed tow to one.

The flap included the skin, fat and fascia elevating it from the tip to the base keeping medial or lateral perforator vessels intact. Figure 1 


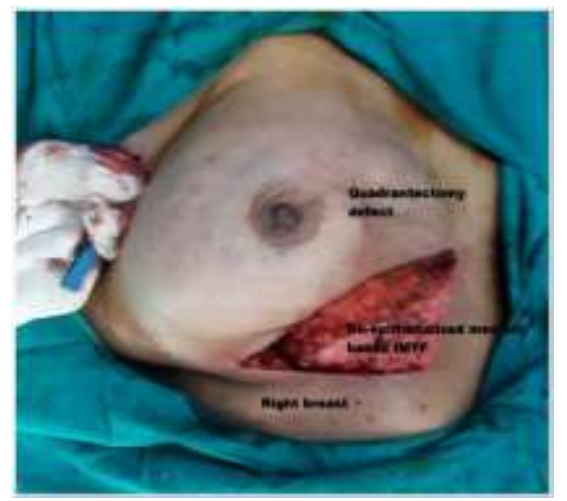

Figure 1:- De-epithelialized IMTF medially based to reconstruct a quadrantectomy defect in the right breast. Once the flaps were dissected off the underlying tissues they were rotated upwards into the breast. The donor site readily closed without tension. We did not need to undermine skin caudal to the flap to close donor sites. Figure 2

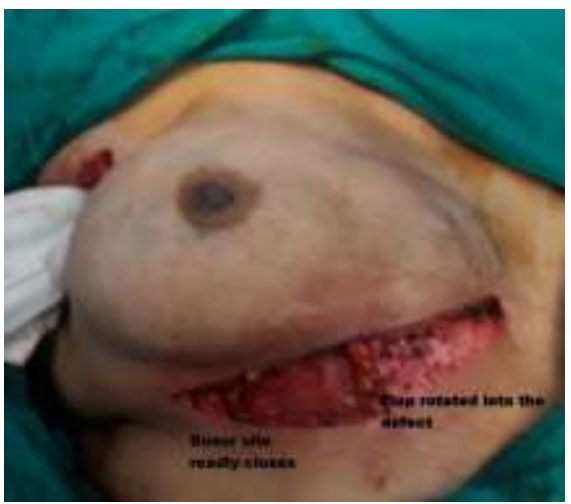

Figure 2:- IMTF rotated into the defect while donor site readily closes without tension.

Before insetting we routinely tested blood supply by incising through the tip of the flap to insure free bleeding otherwise trimming of the tip was done until free bleeding ensued. A suction drain was routinely used for five to seven days.

In order to insure maximum rotation of the flap, the upper incision started at the far medial or the far lateral end of the defect according to the position of the tumor. The lower incision ended exactly at the level of the other end of the defect and did not reach the upper incision end. This ensured a wide oblique base of the flap with maximum rotation and readily closed donor site. Figure 3

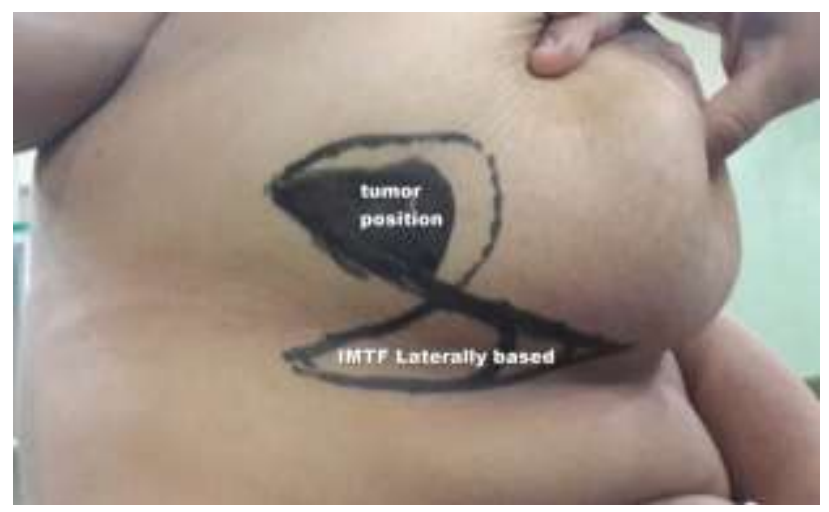

Figure 3:- Laterally based IMTF design.

Some flaps were de-epithelialized to replace tissues under the skin of the breast, or skin was kept to replace breast skin that was removed along with the tumor during resection. Figure 4 


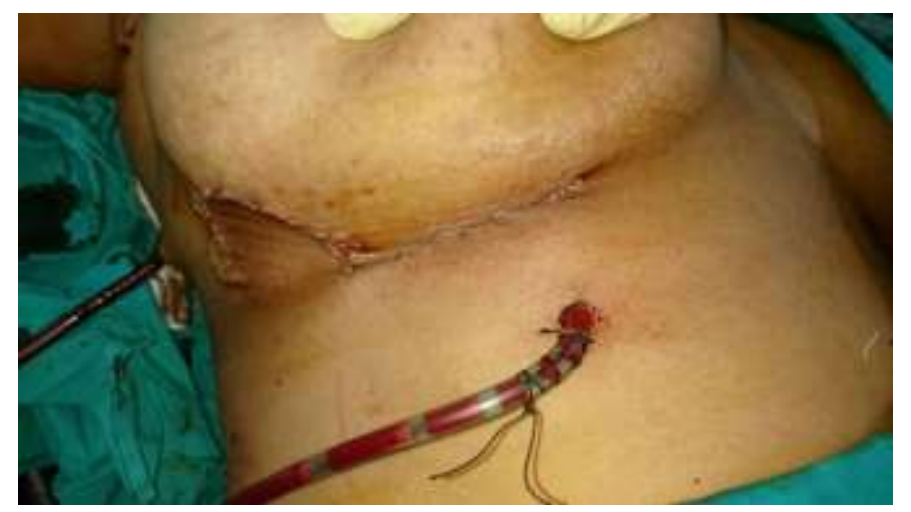

Figure 4:- skin of the flap was kept to replace breast skin that was removed along with the tumor during resection. IML was reconstructed by deep interrupted stitches that incorporated dermis and fascia to the underlying pectoral fascia. No sutures were used to keep the flap attached to the remaining breast tissues. Finally the incision was closed. It was at the IML hidden by the natural breast ptosis. Figure 5

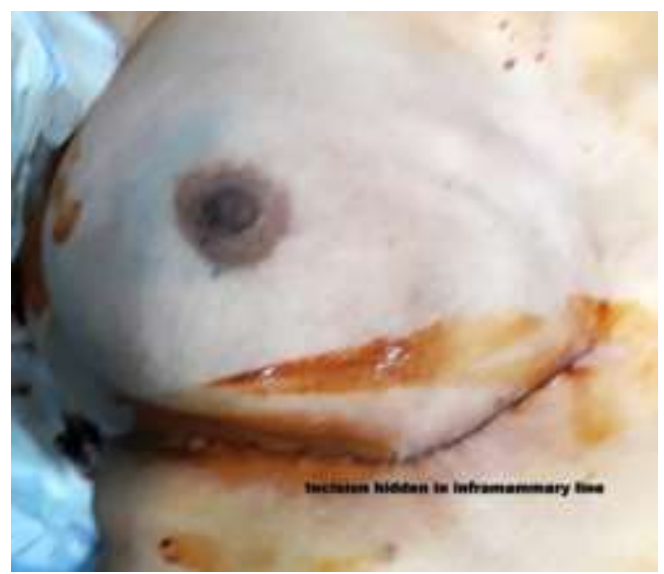

Figure 5:- final incision is hidden in the inframammary line.

All cases received radiotherapy as a part of oncological management in the form of external beam radiation to the whole breast (50 Grays). Five cases had boost therapy to the operative site.

Follow up period was 12 months. Esthetic and oncological results were evaluated at the end of follow up period. Patient satisfaction was obtained by questionnaires into four categories (excellent, very good, good, and unsatisfactory).

\section{Results:-}

All our cases had infiltrating ductal carcinoma in the final pathology report and margins of resection were negative in all cases.

There were no postoperative complications (no seroma, haematoma, wound infection or dehiscence).

Hardening of the tip of the flap occurred in only one patient after boost radiotherapy. Ultrasound examination revealed distortion suggesting fat necrosis which was confirmed by core biopsy. We had to excise this area for histological assessment to rule out the possibility of recurrence.

The appearance of the affected side was very much similar to the other side with perfect esthetic results. Patch effects were not apparent due to the presence of the flap at IML hidden by natural breast ptosis. Figure 6 


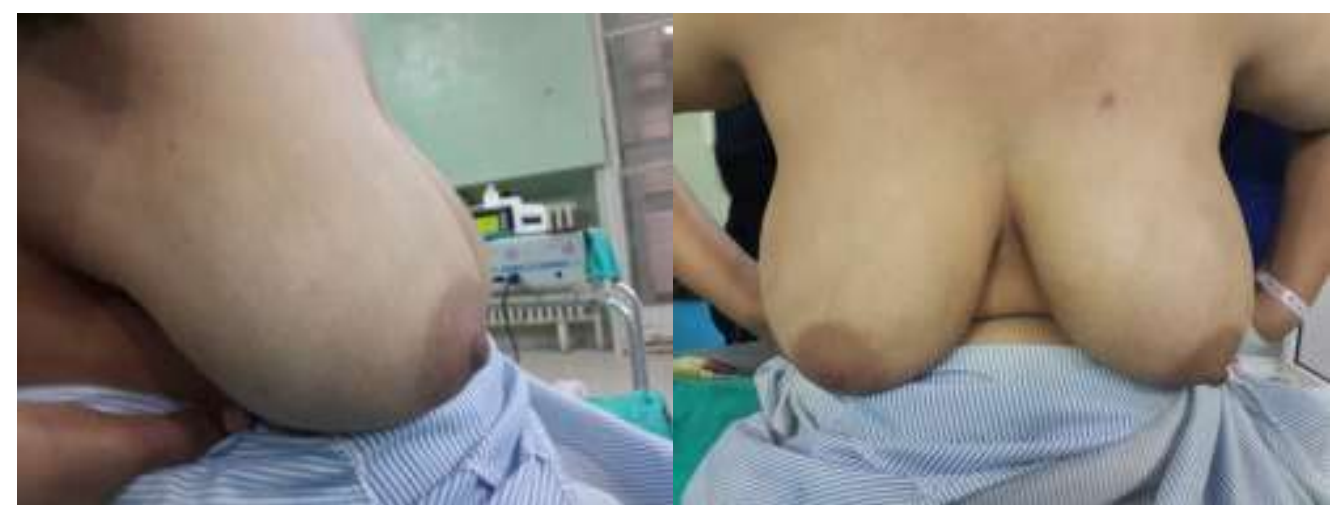

Figure 6:- No change to the appearance of the breast and the incision is hidden.

No patient had tumor recurrence over that period of follow up.

\section{Discussion:-}

Inspired by the innovative nature of oncoplastic breast surgeries and their capabilities to achieve excellent cosmetic results, many techniques were used in our unit in the period from 2007 untill 2015. The majority of these cases were directed against tumors in the upper half of the breast on the account of the prevalence of tumors in the upper breast quadrants.

We tried to use inframammary AFPs described by Ogawa T et al ${ }^{(11)}$. We noticed that the execution of these flaps was difficult because of the undermining of the skin in the inframammary area to isolate the flap. Also because the design of the flap entailed dissection of a tongue shaped flap that was attached to the IML at a very small area that was difficult to maintain. Also the amounts of tissue harvested were little because they were devoid of skin.

Many cases had hardening of tissues after radiotherapy and the rate of fat necrosis was high. Again those cases had to undergo excision of the flap to exclude tumor recurrence after all. Y. Kijima et al reported on a case that was excised three years later because of tumor recurrence with maintained flap viability on histological assessment ${ }^{(12)}$. This was not similar to our experience.

The anatomical study conducted brought some light on the inadequacy of blood supply of these flaps.

Adil Aljarrah et al used a "crescent" shaped inframammary flap for the same purpose but it is only suitable for median defects only ${ }^{(13)}$.

Bjelic-Radisic reported on the use of "epigastric flap" to reconstruct defects in the lower breast ${ }^{(14)}$. This was a case report. He did not report on the design of the flaps, the size and fate of donor site, the arc of rotation and rate of complications.

The previous anatomical study strengthened our belief in the reliability of these flaps. The excellent blood supply, the excess tissues provided by the skin, the lack of skin undermining and excellent cosmetic results are benefits of these flaps.

\section{Conclusion:-}

Anatomical data were very valuable to design flaps with better vascularity and reliability. IMTFs were both safe and adequate to replace defects following BCS with low complications rate and best esthetic outcomes. 


\section{References:-}

1. Franceschini, G., Sanchez, A. M., Di Leone, A., Magno, S., Moschella, F., Accetta, C., \& Masetti, R. (2015). New trends in breast cancer surgery: a therapeutic approach increasingly efficacy and respectful of the patient. Il Giornale Di Chirurgia, 36(4), 145-152. http://doi.org/10.11138/gchir/2015.36.4.145

2. Piper, M., Peled, A. W., \& Sbitany, H. (2015). Oncoplastic breast surgery: current strategies. Gland Surgery, 4(2), 154-163. http://doi.org/10.3978/j.issn.2227-684X.2015.03.01

3. Macmillan, R. D., \& McCulley, S. J. (2016). Oncoplastic Breast Surgery: What, When and for Whom? Current Breast Cancer Reports, 8, 112-117. http://doi.org/10.1007/s12609-016-0212-9

4. Piper, M., Peled, A. W., \& Sbitany, H. (2015). Oncoplastic breast surgery: current strategies. Gland Surgery, 4(2), 154-163. http://doi.org/10.3978/j.issn.2227-684X.2015.03.01

5. Munhoz, A. M., Montag, E., \& Gemperli, R. (2013). Oncoplastic breast surgery: indications, techniques and perspectives. Gland Surgery, 2(3), 143-157. http://doi.org/10.3978/j.issn.2227-684X.2013.08.02

6. Immediate reconstruction using inframammary adipofascial flap of the anterior rectus sheath after partial mastectomy.

7. Yuko Kijima, Heiji Yoshinaka, Tetsuhiro Owaki, Yawara Funasako, Takashi Aikou. Am J Surg. 2007 Jun; 193(6): 789-791. doi: 10.1016/j.amjsurg.2006.06.052

8. Yang, J. D., Lee, J. W., Cho, Y. K., Kim, W. W., Hwang, S. O., Jung, J. H., \& Park, H. Y. (2012). Surgical Techniques for Personalized Oncoplastic Surgery in Breast Cancer Patients with Small- to Moderate-Sized Breasts (Part 2): Volume Replacement. Journal of Breast Cancer, 15(1), 7-14. http://doi.org/10.4048/jbc.2012.15.1.7

9. G. Peeters, B. Cambier, T. Stasch, and S. Grandel, "The exposed breast prosthesis at the infra-mammary region: treatment by local flaps," European Journal of Plastic Surgery, vol. 34, no. 6, pp. 513-516, 2011.

10. Ehab M. Elzawawy, Melad N. Kelada, and Ahmed F. Al Karmouty, "New Possible Surgical Approaches for the Submammary Adipofascial Flap Based on Its Arterial Supply," Anatomy Research International, vol. 2016, Article ID 7696010, 10 pages, 2016. doi:10.1155/2016/7696010

11. Ogawa T, Hanamura N, Yamashita M, Ri Y, Kuriyama N, Isaji S. Usefulness of breast-volume replacement using an inframammary adipofascial flap after breast-conservation therapy. Am J Surg. 2007 Apr;193(4):514-8

12. Y. Kijima, H. Yoshinaka, M. Hirata, A. Nakajo, H. Arima, S. Ishigami, S. Ueno and S. Natsugoe, "Histological Findings of a Local Adipofascial Flap That Was Implanted during Breast Conserving Surgery," Modern Plastic Surgery, Vol. 3 No. 1, 2013, pp. 43-46. doi: 10.4236/mps.2013.31008.

13. Adil Aljarrah, Claude Nos, Rana Nasr, Krishna B. Clough, Anne-Sophie Bats, Fabrice Lecuru. Updated followup of patients treated with the oncoplastic "Crescent" technique for breast cancer. The Breast, Volume 21 , Issue $4,475-479$

14. Bjelic-Radisic. Tumor quadrantectomy and defect remodeling with an epigastric skin flap. In Springer Verlag Vienna 2015: F. Fitzel, P. Schrenk(eds.). oncoplastic breast surgery: a guide to clinical practice. Second edition, capter $11 ; 43-44$. 